\title{
FROM OUTSIDERS TO INSIDERS
}

\author{
GRADUATE ASSISTANT DEVELOPMENT AT STATE \\ COMPREHENSIVE UNIVERSITIES
}

\author{
Katbleen M. Brennan, Laura Cruz, Freya B. Kinner \\ Western Carolina University
}

We assess graduate assistant competency in key skills that employers in and outside of academia value and examine whether these skills are developed in the context of the graduate assistantship (GA) at a specific state comprehensive university. The GAs in our sample rate themselves as competent or very competent on all skills and report their $G A$ experience somewhat influenced or influenced their skill competencies. Furthermore, perception of how one's graduate assistantship influenced skill competency was significantly associated with perceived skill competency level. Based on these findings, we discuss distinct gaps that could be addressed to facilitate GA development at state comprehensive universities.

0

If you are a typical faculty member, odds are about fifty-fifty whether you received training as a graduate assistant (GA) outside of your disciplinary course work (Nyquist, Abbott, Wulff, \& Sprague, 1991). Those odds are longer the further back you received your $\mathrm{PhD}$. You are even less likely to have received such training if your highest degree is a master's degree and less likely still if you received your master's degree from a state comprehensive university (SCU). In many ways, graduate students at SCUs 
have been treated as outliers, even outsiders, by researchers and practitioners of graduate student development (Chen, 2003; Hagstrom et al., 2000).

\section{Background}

The role and development of GAs has been overlooked at SCUs, at least in part because it has largely been overlooked everywhere else (Abbott, Wulff, \& Szego, 1989; Wert, 1998). Graduate education as a whole has been one of the last frontiers for research and certainly one of the areas in which the least amount of reform has taken place. The reasons for this are complex, but one possibility is that the impetus for reform began in secondary education and then radiated out to neighboring areas, putting graduate education on the outlying fringe. Another possibility is that tradition has been more cloying in graduate education. Many faculty see graduate training as the last bastion that is truly the domain of the academic scholar, free from outside influences that may sully the purity of its imparting of knowledge.

The outsider or outlier status can also apply to SCUs. In his book, Teaching at the People's University, Bruce Henderson (2006) suggests that SCUs lack the clout and funding of research universities and the specific mission or traditions of community colleges or liberal arts colleges. Henderson argues that when SCUs, born as teachers' colleges, fail, it is because they try too hard to be like these other institutions and do not feel sufficiently comfortable to differentiate their own values and identity. The awkwardness is compounded when examining graduate programs at SCUs. By definition, comprehensive universities offer a variety of graduate programs at the master's level but few, if any, doctoral programs. While most graduate programs are patterned after their counterparts at research universities that do offer $\mathrm{PhDs}$, little to no work has been done to find a distinctive identity for graduate programs in fulfilling the mission of SCUs (Freeman \& Schmidt, 2000).

Graduate student development on the whole became a topic of conversation in the 1980s (Chism, 1998). By the 1990s, the National Survey of Teaching Assistant Training Programs and Services indicated that 71 percent of responding institutions had developed specific programs for graduate student development, but the majority of these were less than five years old (Lambert \& Tice, 1993). Today the conversation has been extended to include GAs in broader conversations about the future of higher education and the raised profile of faculty and teacher professional development. When these efforts have been productive, they have been 
aimed largely at the doctoral and research universities. For example, Border and von Hoene (2010) have recently been working on a second national-level study designed to provide a taxonomy of best practices in graduate student certificate programs, but they have included a limited number of SCUs in their surveys. This is understandable, as these graduate programs are often considerably smaller and are generally limited to the master's level, but student enrollment in these programs is rising and is likely to continue rising at a faster rate than at other institutional types.

The challenge in looking at graduate development at SCUs comes from the diversity of goals and outcomes for graduate education. In the case of doctoral-granting institutions, the traditional, primary purpose of the $\mathrm{PhD}$ is to train future faculty for work in academia. While a study of career objectives for master's degree-seeking students has yet to be done on the national level, most evidence suggests that these programs must serve a variety of other outcomes for their students, including academia. Even at the PhD level, there are scholars who argue that graduate student development should include preparation for roles outside academia, especially given the stagnation in current academic job markets (Austin \& Wulff, 2004; Conn, 2010). This need is even more acute for SCUs where academic careers are less of a common denominator. A graduate student survey at the University of Nebraska-Lincoln, for example, showed that doctoral students chose academic career goals across the board, but that master's-level students looked for careers in industry (22.9 percent), consulting (22.9 percent), and entrepreneurship (22.9 percent) (Bellows \& Weissinger, 2005). According to the recent Pathways through Graduate School report, commissioned by the Council of Graduate Schools and ETS, approximately one-third of graduate students with master's degrees work in business and roughly one-fourth in teaching or faculty positions (Commission on Pathways, 2012).

A number of major studies in the 1990 s demonstrated clear disconnects between the careers that graduate students eventually choose and the preparation they receive for them (Golde \& Dore, 2001; Nerad, 2004). While 65 percent of the over four thousand survey respondents for the 2000 survey on doctoral education and career preparation indicated that their programs prepared them well for research and research-related activities, they were less confident in their preparation for various aspects of classroom teaching (National Association of Graduate-Professional Students, 2000). They expressed the least confidence in their training for participating in university citizenship (12.7 percent) and community outreach (13.8 percent). However, only 31.8 percent of the respondents said they participated in nonacademic job search opportunities. 
Open-ended responses indicated that there were often disincentives for exploring nonacademic options.

The gap between preparation and careers that the survey indicated has led to concerted efforts in graduate student development, particularly in changing older models of training teaching assistants to more multifaceted preparing future faculty (PFF) initiatives (Gaff, 2002). Most PFF programs consist of a mix of formal and informal opportunities designed to address multiple aspects of academic work, and they provide this support in multiple formats, including voluntary, certificate, online, and credit-based programs (Lambert \& Tice, 1993). The field also includes career development opportunities, incorporating training in teamwork, communication, conflict resolution, project management, and other jobrelated skills (Border, 2006). Even with expanding opportunities, graduate student development remains largely the domain of doctoralgranting institutions in spite of the fact that graduate students at SCUs also participate in all of these aspects of academic work, but usually with a shorter time frame for development.

Global assessment of the effectiveness of these strategic changes in graduate student development is in the beginning phases, though individual programs are usually well assessed and regularly evaluated. Broader discussions are currently focused on desired outcomes or objectives from which to form the basis of objective measurement across campuses, but under the leadership of the Professional and Organizational Development (POD) network, progress continues to be made (Bellows, 2008). A handful of studies suggest that institutions that offer graduate student development programs benefit in the areas of recruitment, retention, and job placement for their graduates (DeNeef, 1996; Lovitts \& Nelson, 2000). In particular, measures of graduate student satisfaction tend to increase proportionately with the number of available graduate student development opportunities (Lovitts, 2004). At least on the surface, there seems to be no reason that institutions that do not confer doctoral degrees could not join in these benefits, but the graduate development programs would need to be adjusted to fit the career goals and expectations of students at SCUs and other master's-level universities.

At the SCU considered in this study, GAs work largely in two areas: teaching and research. A graduate development program exists, but like many other SCUs, the program is underdeveloped compared to those at research institutions where PFF initiatives are under way. For the purposes of a needs assessment, the Center for Teaching and Learning partnered with the Graduate School to survey GAs regarding their perceptions of career skills gained as part of their assistantships. The information was 
also intended to address gaps in the assistantship experience. As a case study, these data are not representative of the experience of GAs at all SCUs. However, its findings may be used to start the conversation. That being said, the purpose of this study is to begin to advance our understanding of graduate student development at SCUs.

\section{Method}

\section{Data}

In April 2010, an electronic survey was sent to all graduate students $(N=302)$ at an SCU in the southeastern United States who were employed as a GA at some point during the 2009-2010 academic school year. The survey asked the GAs to rate their competency in twenty-one transferable skills identified by the National Association of Colleges and Employers (NACE) Job Outlook Survey as important to a wide range of employers. (See table 13.1 for a listing of skills.) Each year, NACE surveys employers about employment-related issues in order to project the market for new graduates and to assess a variety of conditions that may influence that market (NACE, 2011). These versatile skills are the foundation of a variety of work, and students graduating with master's degrees from SCUs have a high likelihood of seeking employment in a wide range of jobs. Thus, it is crucial for SCUs to address these skills within the context of the graduate assistantship experience.

Respondents were also asked to rate and identify specific examples of how their GA experience influenced their competency level for each skill and comment on how effectively their mentor influenced the development of their transferable skills. GAs were also asked how well their GA duties fit their expectations of the position.

\section{Sample}

A total of 114 GAs completed a questionnaire for a response rate of roughly 34 percent, adjusting for missing data. This response rate is quite respectable and surpasses that of many general population surveys (Cook, Heath, \& Thompson, 2000). The majority ( 57 percent) of respondents reported they had been employed as a GA for two semesters, although 20 percent reported being employed as a GA for four semesters. Respondents were asked to select all GA job classifications that apply; most ( 57 percent) were employed as a research graduate assistant, while 32 percent, 28 percent, and 24 percent, respectively, were employed as a 
lab GA, administrative GA, or teaching GA (instructor of record). The characteristics of the sample resemble those in the institution's population of GAs for 2009-2010.

\section{Variables}

For each of the twenty-one skills studied, respondents were asked to describe their level of competency on a four-point scale and the degree to which their experience as a GA influenced their competency in each skill. In addition to measuring the competencies individually, we also consider a twenty-one-item index measure of overall skill competency level (alpha $=.859$ ) and a twenty-one-item index measure of overall perceived influence of the graduate assistantship on skill competency level (alpha $=.949$ ).

GAs were asked how effectively their mentor, advisor, or supervisor influenced the development of their transferable skills $(1=$ Not Very Effectively, 2 = Somewhat Effectively, 3 = Moderately Effectively, $4=$ Very Effectively). In addition, they were asked to comment on how effectively their mentor, advisor, or supervisor influenced the overall development of their transferable skills.

Respondents were asked how well their GA duties fit their expectations of the position $(1=$ Not at All, $2=$ Somewhat Well, $3=$ Moderately Well, and $4=$ Very Well). They were also asked to provide an openended comment, if appropriate, about how well their GA duties fit their expectations of the position.

\section{Analysis}

Our analyses focus on assessing how competent GAs are in transferable skills deemed valuable by a range of employers, as well as how their graduate assistantship at an SCU has influenced their competency. We offer a snapshot of our sample GAs' preparedness for employment outside academia and propose suggestions for improving training and development of GAs at SCUs.

\section{Results}

Descriptive statistics for the twenty-one GA self-reported skill competencies are represented using medians and category percentages (see table 13.1). All self-reported skill competencies have median scores of 3 or 4 , indicating that most GAs considered themselves competent (3) or very 


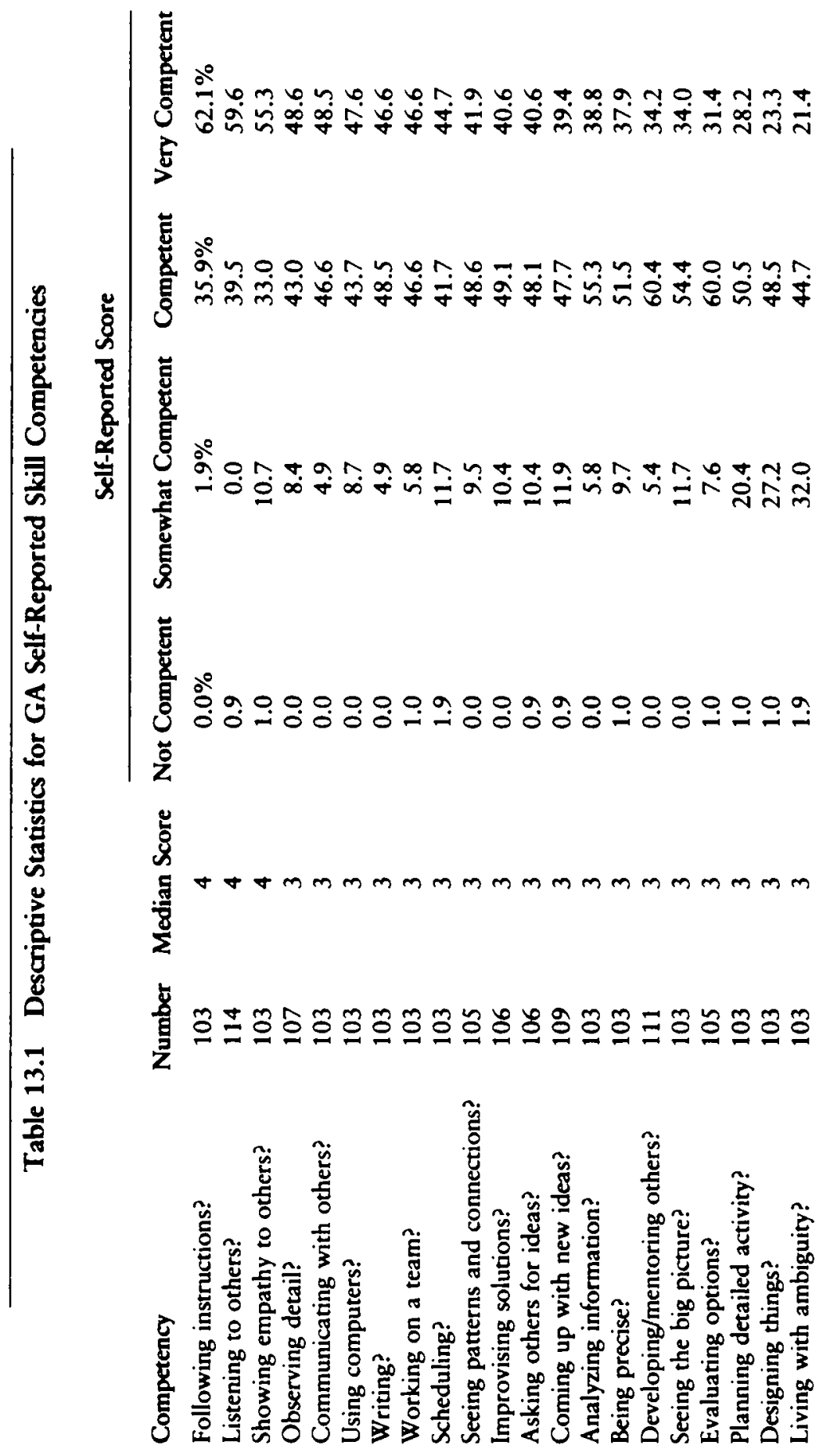


competent (4) on each surveyed skill competency. This is also reflected in the percentages for each skill competency. GAs rate themselves most competent in following instructions and listening to others and least competent in living with ambiguity, designing things, and planning detailed activity.

Descriptive statistics for the influence of the GA experience on selfreported skill competencies are also represented using medians and category percentages (see table 13.2). Median results indicate that GAs reported their GA experience somewhat influenced (2) or influenced (3) their skill competencies. As indicated by the percentages, the skill competencies that were most influenced by the GA experience were communicating with others, developing/mentoring others, improvising solutions, analyzing information, coming up with new ideas, and scheduling. Those least influenced by the GA experience were writing, designing things, using computers, working in a team, and showing empathy to others.

Individual results from table $\mathbf{1 3 . 2}$ for the impact of the GA experience on skill competencies are consistent with GA responses to, "How effectively did your mentor, advisor, and/or supervisor influence the development of your transferable skills?" The median response indicates that GAs felt that their mentors were moderately effective in influencing their transferable skills (median $=3$ ). Open-ended responses included common descriptions of mentors influencing GAs across an array of issues. One GA reported, "My mentor constantly addressed how my assistantship was creating and developing transferable skills. She also addressed how these skills may be desirable in the future in both academia and the workplace. She often offered and encouraged numerous helpful suggestions about future career paths and opportunities in both the professions of teaching and editing/publishing." Other GAs commented, "The mentor I observed taught me many things I still use, and I still ask her for advice even though I have a different mentor," and, "Truthfully, I would be lost without my advisor and his continued support."

In addition to these broad-based supports, students stated their mentors helped them communicate well with others. Examples include: "My two main mentors encouraged me to remain professional and dedicated, and they, along with my other mentors, helped me with skills to interact with people in order to complete my work as a GA," and, "I learned by my professors' example how best to communicate and tackle challenges." Often graduate students commented that communication skills developed during their GA experience were helpful for teaching: "I was given guidance in how to deal with students, how to give helpful feedback when grading papers, and how to best approach different course contents." 


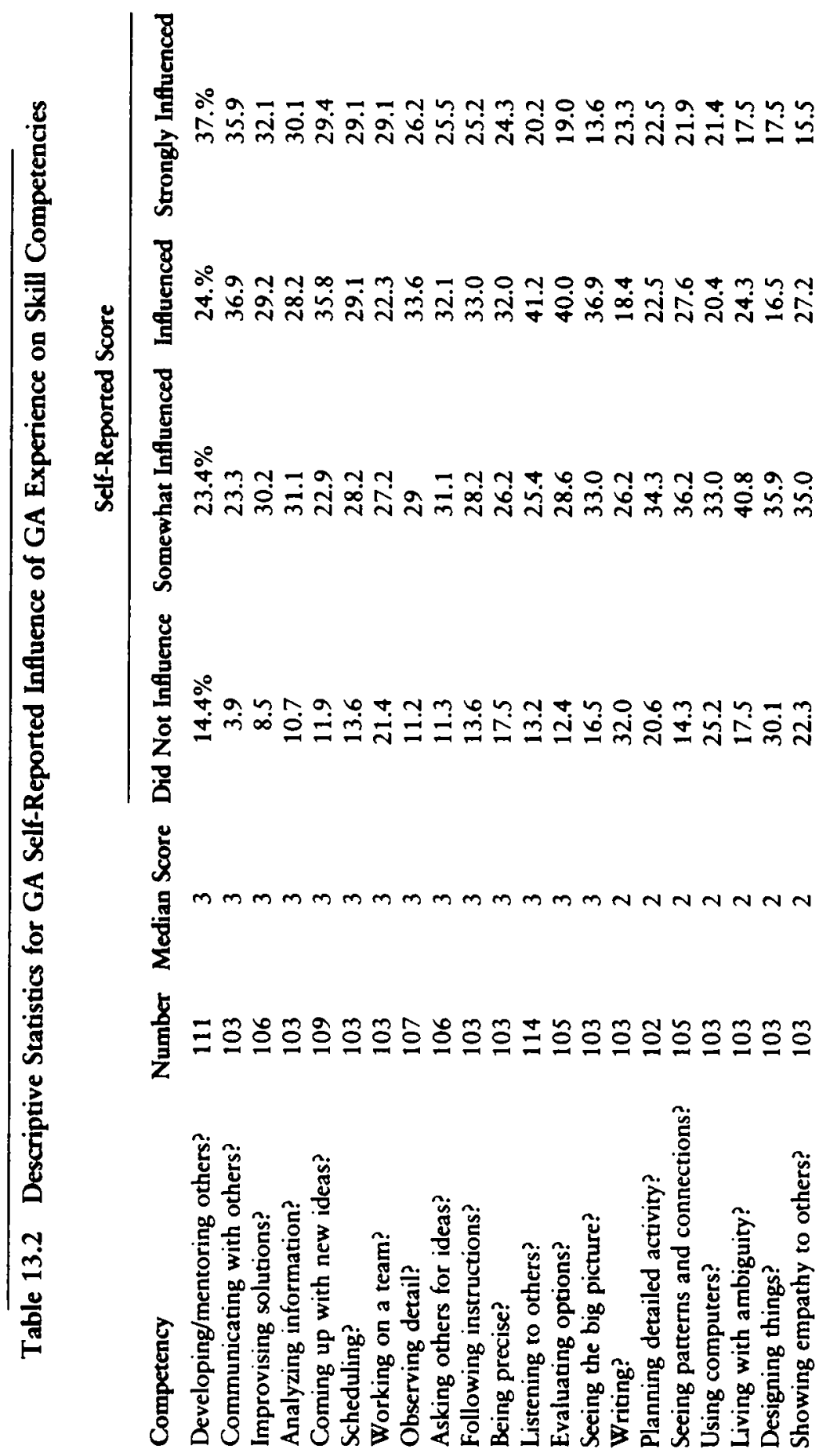


Regarding GA position fit to expectations, the median response indicates that GAs felt the position duties fit their expectations. Most indicated that the position met their expectations very well (median $=4$ ). Likewise, open-ended responses reaffirmed that respondents found the job to be "challenging but not overwhelming" with "basic duties [that] were in line with my expectations."

Dependence between influence of the graduate assistantship and perceived skill competency variables is represented by gamma (see table 13.3). A statistically significant gamma value indicates how much we would reduce error in predicting the self-reported competency when we take the perceived influence of the graduate assistantship into account. The $t$-statistic and corresponding $p$-value indicate whether the relationship is statistically significant. The data in table 13.3 indicate statistically significant relationships for twelve of the twenty-one variables, based on a

Table 13.3 Gamma Values for Association between Influence of GA Experience on Skill Competencies and Self-Reported Skill Competencies

Influence of GA Experience on

Competency: Your Experience as

a GA Influenced Your

Competency in ...

Coming up with new ideas?

Improvising solutions?

Designing things?

Developing/mentoring others?

Asking others for ideas?

Communicating with others?

Planning detailed activity?

Evaluating options?

Analyzing information?

Seeing patterns and connections?

Scheduling?

Working in a team?

Seeing the big picture?

Living with ambiguity?

Writing?

Showing empathy to others?

Following instructions?

Being precise?

Listening to others?

Using computers?

Observing detail?
Number Gamma Value $t$-Value $p$-Value

$\begin{array}{rrrr}109 & 0.403 & 3.564 & 0.000 \\ 106 & 0.501 & 4.099 & 0.000 \\ 103 & 0.479 & 4.212 & 0.000 \\ 111 & 0.433 & 3.345 & 0.001 \\ 106 & 0.367 & 3.041 & 0.002 \\ 103 & 0.424 & 3.018 & 0.003 \\ 102 & 0.333 & 2.766 & 0.006 \\ 105 & 0.384 & 2.669 & 0.008 \\ 103 & 0.336 & 2.414 & 0.016 \\ 105 & 0.290 & 2.176 & 0.030 \\ 103 & 0.272 & 2.166 & 0.030 \\ 103 & 0.277 & 2.021 & 0.043 \\ 103 & 0.258 & 1.948 & 0.051 \\ 103 & 0.239 & 1.817 & 0.069 \\ 103 & 0.207 & 1.561 & 0.119 \\ 103 & 0.206 & 1.487 & 0.137 \\ 103 & 0.143 & 0.961 & 0.337 \\ 103 & 0.124 & 0.874 & 0.382 \\ 114 & 0.057 & 0.399 & 0.690 \\ 103 & -0.026 & -0.199 & 0.843 \\ 107 & 0.054 & 0.099 & 0.921\end{array}$


$p$-value of 0.05 or less. Eight of these twelve gamma values are significant at the $p<.01$ level and indicate a moderately strong, positive influence of the graduate assistantship on the skill competency level. The remaining four gamma values are significant at the $p<.05$ level and indicate a weak to moderate positive influence of the graduate assistantship on skill competency level.

The results in table 13.3 indicate that (1) GAs perceive themselves to be at least competent, if not very competent, in all skills, (2) they perceive that their GA experience at least somewhat influenced, if not influenced, their competency in all skills, and (3) a significant association exists between the influence of GA experience on skill competencies and selfreported skill competencies for more than half of the skills under consideration. Based on these findings, we consider the relationship between overall perceived influence of graduate assistantship experience on skill competencies and overall perceived skill competency as represented by two twenty-one item indices.

Table 13.4 presents descriptive statistics for each index. Results indicate GAs' average perception of overall skill competency is higher than their average overall perception of graduate assistantship influence on skill competency. However, results also indicate more diversity in scores for GAs' overall perception of graduate assistantship influence on skill competency.

Table 13.5. presents the results from linear regression analysis of overall skill competency on overall GA influence. Overall perceived influence of graduate assistantship on skill competency development has a significant, positive effect on overall perceived skill competency level. For every one unit increase in perceived overall influence of graduate assistantship on skill development, perceived overall skill competency level increased by .173 units $(p<.001)$. Furthermore, perceived overall influence of graduate assistantship accounts for roughly 12.5 percent of the variance in perceived overall skill competency level.

Table 13.4 Descriptive Statistics for Twenty-One Item Indexes

$\begin{array}{lcccccc} & \text { Median } & \text { Mean } & \text { SD } & \text { Range } & \text { Minimum } & \text { Maximum } \\ \begin{array}{l}\text { Overall GA influence } \\ \text { on skill competency } \\ (n=102)\end{array} & 55.00 & 55.21 & 14.88 & 56.00 & 28.00 & 84.00 \\ \begin{array}{l}\text { Overall skill } \\ \text { competency }\end{array} & 69.00 & 69.27 & 7.01 & 35.00 & 49.00 & 84.00 \\ (n=103) & & & & & & \\ & & & & & & \end{array}$


Table 13.5 Linear Regression of Overall Skill Competency on Overall GA Influence $(N=102)$

$\begin{array}{lccc} & \text { B } & \text { SE } & \text { Beta } \\ \text { Overall GA Influence } & .173 * * * & .044 & .366 \\ \text { Constant } & 59.697 & 2.515 & \\ \text { Adjusted } R^{2} & .125 & & \\ \text { *p<.05, * } p<.01, * * *<<.001 . & & & \end{array}$

\section{Discussion}

The findings from this study suggest that the GA development experience at this SCU may not be uniform, which seems to be the case at other institutions as well (Anderson \& Swazey, 1998; Redd, 2006). This is most likely due to the fact that graduate student development at the SCU in question mostly occurs in the context of individual graduate programs rather than an institutional graduate development program, many of which last only one day (Gray \& Buerkel-Rothfuss, 1991). Most studies of graduate student socialization indicate the need to facilitate sustained development over time and across the majot roles that graduate students typically inhabit (LaPidus, 1997), while at the same time taking institutional context into account. Weidman, Twale, and Stein (2001) suggest that institutional culture and peer climate are decisive factors in the graduate school experience. Graduate students at SCUs have shorter time frames in which to foster meaningful peer collaboration, as most programs last two years or less. In addition, they are more likely to interact with peers whose future plans do not include academia. Successful graduate development programs at SCUs need to take into account this distinctive contextual mixture.

The imperfect fit between the roles, context, and expectations of graduate students and their experiences at SCUs is evident in our survey results. One of the most noticeable gaps is between perception and reality of skill development. According to a recent comprehensive survey, undergraduate students, now more than ever before, rate their academic skills considerably higher than academic achievement indicators would suggest (Twenge, Campbell, \& Gentile, 2011). Our findings indicate that a similar overconfidence may apply to graduate students, who ranked themselves competent or highly competent in all of the skills represented in our study. It is likely that this gap will only grow larger as current 
undergraduates transition into graduate study. This finding dovetails with other studies of self-reported abilities for graduate students, in which the majority of graduate student respondents ranked their teaching and other academic abilities at the highest levels prior to graduation (Meitl, 2008; Tompkins \& Dimiduck, 2010). The phenomenon is sufficiently persistent that a minor field of study focused on managing overconfidence (at both the undergraduate and graduate levels) has emerged (Kruger \& Dunning, 1999). In terms of building models for graduate student development, this gap between perception and reality represents a significant obstacle and potential point of resistance.

Our findings suggest a second notable gap in the communication of expectations, a factor that is often cited as significant in determining graduate student attrition rates (Golde \& Dore, 2001). The majority of graduate students in this study come from undergraduate programs at SCUs within the same state. Many are the first in their families to attend graduate school, which may affect their expectations of the graduate experience. While many students found their GA experience consistent with expectations, as evidenced by a median score indicating GAs felt position duties fit their expectations "very well," others' experiences differed from what they anticipated. In open-ended responses, these students were frequently surprised by their GA duties, in both positive and negative ways. Regarding positive examples, GAs reported, "I was required to take more of a leadership position," and, "Working under [supervisor] has shown me the many sides of teaching ... and [my field] better than I expected." Still other GAs stated their duties were worse than anticipated: "I was hoping to have more of a learning experience. I don't often feel challenged enough or a benefit to the department," and, "With the graduate research assistantship, I was disappointed with the limited interaction I had with my professor. I was eager to do research, but was not given as many tasks to complete or as much involvement with the research and writing as I had hoped."

At SCUs, perhaps more than at other institutional types, there is a need for foundational conversations about the nature of the graduate school experience. Part of the burden of responsibility for communicating these expectations rests on the faculty mentor or advisor. Many studies have emphasized the pivotal role of the mentor in graduate student development (Bair \& Haworth, 1999; Boyle \& Boice, 1998; Lovitts \& Nelson, 2000; Park, 2004; Young \& Bippus, 2008; Zhao, Golde, \& McCormick, 2005), and graduate student satisfaction with mentor/advisor relationships tends to be higher at master's-level institutions (Conrad, Haworth, \& Boulevard-Millers, 1993), a conclusion that is supported by previously 
discussed positive orientations towards advisors found in open-ended responses to our survey.

However, the importance of the mentoring relationship was also evident in responses that depicted mentors in a less-than-positive light. Some students struggled with lack of time with their mentor or lack of interaction: "[Supervisor] never ha[d] time for me, never interact[ed] with me, [taught] me, or allow[ed] me to help him with anything," and, "We didn't work together as often as I anticipated." These responses suggest the importance of faculty training for graduate student development. At SCUs, faculty members generally learn to mentor graduate students from their experience with their own mentors at doctoral-granting institutions, but that experience may be less applicable to the SCU environment. Few receive specific training in skills and experience needed in nonacademic job markets unless they had worked previously as practitioners in the field. This gap in faculty training is compounded by higher workload expectations that often characterize academic careers at SCUs, resulting in less time for faculty development and training, much less for their advisees (Henderson, 2006). Research on faculty expectations for graduate student work and learning outcomes might prove to be enlightening.

One of the strongest findings of our study is the clear disconnect between how students perceive or rate their transferable skills and how well they are able to identify, articulate, and use these skills. Most students identified teaching and research/scholarship/creative works as their primary responsibilities as GAs, but these experiences did not always translate into the transferable skills inventory. A handful mentioned help with career goals as a benefit to their experience, but largely in the context of teaching or research. For example, one respondent stated, "The teaching aspect.... allowed me to experience firsthand the career I've chosen to pursue." This suggests a clear need for graduate development programs to include transferable skill education as an integral part of their offerings, a competency that traditional assistantships are not providing (Nettles \& Millet, 2006).

\section{Conclusion}

The self-reported competency in transferable skills found in our survey data provides important insight regarding GAs' perceived preparedness for future employment and perception of the degree of influence the assistantship had on level of preparedness. However, because our study looked at a cross-section of one cohort of graduate students at one SCU, it is limited in its applicability. Further research aimed at advancing 
understanding of graduate student development at SCUs should look at both broadening and deepening its scope. First and foremost, subsequent studies should include comparisons with other SCUs and other institutional types to reveal broader patterns of graduate experiences. Second, future studies should include longitudinal data to address generational issues suggested by the survey results, including information about preand postexperiences of the cohorts in question. Finally, more focused qualitative studies could be used to explore the lack of understanding regarding transferable skills revealed by our study. While our study provides a snapshot of how students view their current experiences, this does not immediately translate into appropriate practices for addressing future issues that arise. Further study is necessary to determine how to improve that experience for both current and future contexts.

This study represents a first step toward conceptualizing a model for graduate student development at SCUs. The results strongly suggest that there are distinct obstacles, cultural and social constructs, and gaps in communication and expectations in institutions that do not primarily train future faculty but are equally worthy of study, attention, and support. As we join broader movements to develop effective models for graduate student development at all levels, both $\mathrm{PhD}$-granting institutions and master's-level institutions can learn much from one another in fostering viable, productive, and successful graduate students. This common commitment means turning outsiders into insiders.

\section{REFERENCES}

Abbott, R. D., Wulff, D. H., \& Szego, C. K. (1989). Review of research on TA training. In J. Nyquist \& R. Abbott (Eds.), New directions for teaching and learning: No. 39. Teaching assistant training in the 1990s (pp. 111-124). San Francisco, CA: Jossey-Bass.

Anderson, M. S., \& Swazey, J. P. (1998). Reflections on the graduate student experience: An overview. In M. S. Anderson (Ed.), New directions for higher education: No. 101. The experience of being in graduate school: An exploration (pp. 3-13). San Francisco, CA: Jossey-Bass.

Austin, A. E., \& Wulff, D. H. (2004). The challenge to prepare the next generation of faculty. In D. H. Wulff \& A. E. Austin (Eds.), Paths to the professoriate: Strategies for enriching the preparation of future faculty (pp. 3-16). San Francisco, CA: Jossey-Bass.

Bair, C. R., \& Haworth, J. G. (1999). Doctoral student attrition and persistence: A meta-synthesis of research. Paper presented at the annual meeting of the Association for the Study of Higher Education, San Antonio, TX. 
Bellows, L. (2008). Graduate student professional development: Defining the field. Studies in Graduate and Professional Student Development, 11, 2-19.

Bellows, L.L.B., \& Weissinger, E. (2005). Assessing the academic and professional development needs of graduate students. In S. Chadwick-Blossey \& D. Reimondo Robertson (Eds.), To improve the academy: Resources for faculty, instructional, and organizational development, Vol. 23 (pp. 267-83). Bolton, MA: Anker.

Border, L.L.B. (2006). Two inventories for best practice in graduate student development. Journal on Excellence in College Teaching, 17, 277-310.

Border, L.L.B., \& von Hoene, L. M. (2010). Graduate and professional student development programs. In K. J. Gillespie, D. L. Robertson, \& W. Bergquist (Eds.), A guide to faculty development (pp. 330-331). San Francisco, CA: Jossey-Bass.

Boyle, P., \& Boice, B. (1998). Best practices for enculturation: Collegiality, mentoring, and structure. In M. S. Anderson (Ed.), The experience of being in graduate school: An exploration (pp. 87-94). San Francisco, CA: JosseyBass.

Chen, D. (2003). A classification system for metaphors about teaching. Journal of Physical Education, Recreation, and Dance, 74(2), 24-31.

Chism, N. (1998). Preparing graduate students to teach: Past, present and future. In M. Marinchovich, J. Prostko, \& F. Stout (Eds.), The professional development of graduate teaching assistant (pp. 1-18). Bolton, MA: Anker.

Commission on Pathways through Graduate School and Careers. (2012), Pathways through graduate school and careers. Retrieved from http://www.ets .org/d19574/19089_PathwaysReptqp.pdf

Conn, P. (2010, April 14). We need to acknowledge the realities of employment in the humanities. Chronicle of Higher Education. Retrieved from http:/l chronicle.com/article/We-Need-to-Acknowledge-the/64885/

Conrad, C. F., Haworth, J. C., \& Boulevard-Millers, S. (1993). A silent success: Master's education in the United States. Baltimore, MD: Johns Hopkins University Press.

Cook, C., Heath, F., \& Thompson, R. L. (2000). A meta-analysis of response rates in web- or Internet-based surveys. Educational and Psychological Measurement, 60(6), 821-836.

DeNeef, A. L. (1996). The lessons of PFF concerning the job market. Washington, DC: Association of American Colleges and Universities and Council of Graduate Schools.

Freeman, P. R., \& Schmidt, J. C. (2000). An interdisciplinary teaching assistant training program at an MA institution. Journal of Graduate Teaching Assistant Development, 7(3), 126-141. 
Gaff, J. G. (2002). Preparing future faculty and doctoral education. Change, 34(6), 63-66.

Golde, C. M., \& Dore, T. M. (2001). At cross purposes: What the experiences of today's doctoral students reveal about doctoral education. Retrieved from http:/www.phd-survey.org

Gray, P. L., \& Buerkel-Rothfuss, N. (1991). Teaching assistant training: A view from the trenches. In J. D. Nyquist, R. D. Abbott, D. H. Wulff, \& J. Sprague (Eds.), Preparing the professorate of tomorrow to teach (pp. 40-51). Dubuque, LA: Kendall/Hunt.

Hagstrom, D., Hubbard, R., Hurtig, C., Mortola, P., Ostrow, J., \& White, V. (2000). Teaching is like ... ? Educational Leadership, 57(8), 24-27.

Henderson, B. (2006). Teaching at the people's university: An introduction to the state comprehensive university. Bolton, MA: Anker.

Kruger, J., \& Dunning, D. (1999). Unskilled and unaware of it: How difficulties in recognizing one's own incompetence lead to inflated self-assessments. Journal of Personality and Social Psychology, 77, 1121-1134.

LaPidus, J. B. (1997). Doctoral education: Preparing for the future. Jourmal of the American Physical Society, 6(11), 8.

Lambert, L. M., \& Tice, S. L. (1993). Preparing graduate students to teach: A guide to programs that improve undergraduate education and develop tomorrow's faculty. Washington, DC: AAHE.

Lovitts, B. (2004). Research on the structure and process of graduate education: Retaining students. In D. H. Wulff \& A. E. Austin (Eds.), Paths to the professioriate: Strategies for enriching the preparation of future faculty (pp. 115-136). San Francisco, CA: Jossey-Bass.

Lovitts, B. E., \& Nelson, C. (2000). The hidden crisis in graduate education: Attrition from Ph.D. programs. Academe, 86(6). Retrieved from http:// www.aaup.org/AAUP/pubsres/academe/2000/ND/Feat/lovi.htm

Meitl, J. W. (2008). Graduate teaching assistant (GTA) development. Unpublished master's thesis, Oregon State University, Corvallis, Oregon.

National Association of Colleges and Employers. (2011). Job outlook 2012. Bethlehem, PA: Author.

National Association of Graduate-Professional Students. (2000). The 2000 National Doctoral Program Survey. Retrieved from http $/ / w w w . n a g p s . o r g$ /survey 2000

Nerad, M. (2004). The PhD in the US: Criticisms, facts, and remedies. Higher Education Policy, 17(2), 183-199.

Nettles, M. T., \& Millett, C. M. (2006). Three magic letters: Getting to PhD. Baltimore, MD: Johns Hopkins University Press.

Nyquist, J. D., Abbott, R. D., Wulff, D. H., \& Sprague, J. (1991). Preparing the professoriate of tomorrow to teach. Dubuque, IA: Kendall/Hunt. 
Park, C. (2004). The graduate teaching assistant: Lessons from a North American experience. Teaching in Higher Education, 9(3), 349-361.

Redd, K. E. (2006). Future shock! How immigration and demographic trends could affect financial aid and college enrollment. Student Aid Transcript, $17(2), 20-27$.

Tompkins, L. J., \& Dimiduck, K. (2010). Confident or overconfident: Changes in the self-reported confidence levels of new teaching assistants pre-and posttraining. Paper presented to the annual ASEE (St. Lawrence Section) conference, Louisville, KY.

Twenge, J. M., Campbell, W. K., \& Gentile, B. (2011). Generational increases in agentic self-evaluations among American college students, 1966-2009. Self and ldentity, 1(1). doi:10.1080/15298868.2011.576820

Weidman, J., Twale, D., \& Stein, E. (2001). Socialization of graduate and professional students in higher education: A perilous passage? San Francisco, CA: Jossey-Bass.

Wert, E. (1998). Foreword. In M. Marincovich, J. Prostko, \& F. Stout (Eds.), The professional development of graduate teaching assistants (pp. xvii-xxii). Bolton, MA: Anker.

Young, S. L., \& Bippus, A. M. (2008). Assessment of graduate teaching assistant (GTA) training: A case study of a training program and its impact on GTAs. Communication Teacher, 22(4), 116-129.

Zhao, C., Golde, C. M., \& McCormick, A. C. (2005). More than a signature: How advisor choice and advisor behavior affect doctoral student satisfaction. Paper presented at American Educational Research Association Annual Meeting, Montreal, Canada. 